\title{
FIRE PROTECTION OF STEEL ELEMENTS USING LIGHTWEIGHT HYBRID CEMENT MORTAR
}

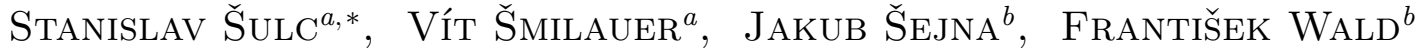 \\ ${ }^{a}$ Czech Technical University in Prague, Faculty of Civil Engineering, Department of Mechanics, Thákurova 7, \\ 16629 Prague 6, Czech Republic \\ ${ }^{b}$ Czech Technical University in Prague, Faculty of Civil Engineering, Department of Steel and Timber \\ Structures, Thákurova 7, 16629 Prague 6, Czech Republic \\ * corresponding author: stanislav.sulc@fsv.cvut.cz
}

\begin{abstract}
Material properties of steel structures are significantly reduced at high temperatures, so a fire protection has strong positive impact on the fire resistance of the structure. Fire resistance of steel elements can be increased using a layer of cement-based materials as a fire protection. Most of commonly used cement-based materials do not withstand high temperatures without noticeable reduction of mechanical properties. Hybrid cement showed some interesting properties in the way of resistance to high temperatures and adhesion to steel surfaces, thus its behavior during fire exposure should be investigated. One experimental analysis with numerical simulation is presented in this article. It examines thermal material properties of lightweight hybrid cement mortar with expanded perlite from a simple experiment with a lab gas burner.
\end{abstract}

KeYwords: Fire protection, fire resistance, hybrid cement.

\section{INTRODUCTION}

Mechanical behaviour of steel structures is very sensitive to high temperatures $[1,2]$ and it is essential to protect steel structures from fire exposure. There are various ways of such protection based on creating physical barrier with low thermal conductivity, such as fire-protective paintings, gypsum plasterboard lining or protection using cement-based materials.

This article aims at a relatively new material called "Hybrid cement" (H-cement) [3], produced by company "Považská cementáreň, a. s." in Slovakia. It has ambitions to be used as a fire-protective material, because the preliminary testing of this material by Daxner [4] showed good characteristics at high temperatures compared to commonly used cementbased materials which do not withstand high temperatures without cracking and spalling $[5,6]$. Another one of its advantages is its suitability for steel structures, because it chemically binds to the steel surface, which makes noticeably stronger connection compared to other cement-based materials, but the adhesion itself has not been measured yet.

There were several initial tests made to inspect the material properties. One of these tests is presented in this article. The overall target is to determine advantages of this material, explore and test its possible usages in the structures.

\section{LAB BURNER TEST}

The thermal characteristics of the material during fire exposure can be calculated by analysis of experimental data. As classic experiments in big furnaces are very expensive, the need of more experimental data lead to a small experiment with a lab gas burner.

\subsection{EXPERIMENT DESCRIPTION}

The subject of interest is a H-cement mortar with expanded perlite. The target of this experiment was to determine its thermal conductivity. The composition of this light-weight H-cement mortar is in Table 1 . The amount of expanded perlite was composed of $43 \%$ of fraction $0-1 \mathrm{~mm}$ and $57 \%$ of fraction 1$2 \mathrm{~mm}$. Bulk density of the mixture in fresh state was $437 \mathrm{~kg} \cdot \mathrm{m}^{-3}$, while in the state of the experiment it was $335 \mathrm{~kg} . \mathrm{m}^{-3}$. The bulk density is highly dependent on the level of intensity and duration of mixing, which mills the granulas of expanded perlite, see Figure 1. It may not be the most suitable material for this purpose due to very small mechanical resistance.

\begin{tabular}{lc}
\hline H-cement & $72.1 \mathrm{~g}$ \\
\hline expanded perlite & $9.17 \mathrm{~g}$ \\
plastifier "Stachement 508" & $1,11 \mathrm{~g}$ \\
water & $55,6 \mathrm{~g}$ \\
\hline
\end{tabular}

TABle 1. Composition of H-cement mortar with expanded perlite.

A steel element of $12 \mathrm{~mm}$ thickness was covered with $\mathrm{H}$-cement mortar with expanded perlite from the bottom side. The other sides were covered with mineral wool. See the geometry scheme in Figure 6 and the photos in Figures 2-5. The hot air coming from the bottom of the element was being dissipated using thin steel plate aligned with the bottom side of the element. 


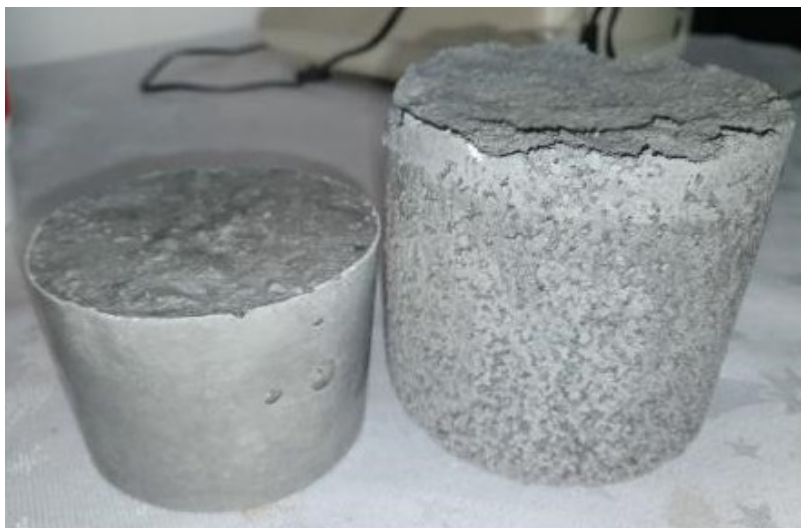

FiguRE 1. Comparison of regular (left) and careful (right) mixing of the mortar / the weight of both elements is the same/.

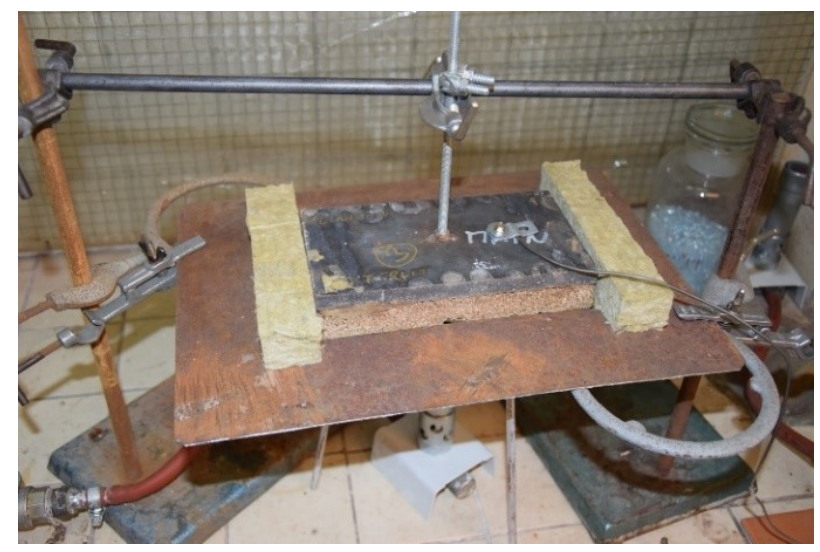

FiguRE 2. Experiment setup.

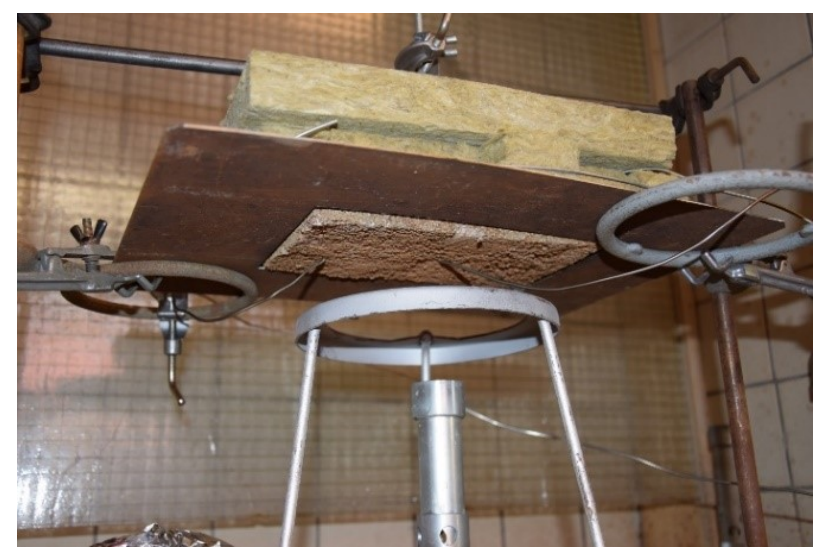

FiguRE 3. Experiment setup.

The properties of used materials are summarized in Tab. 2. Before the experiment was realized, the mortar was being dried in $40{ }^{\circ} \mathrm{C}$ for 9 days, during which the mortar lost $30 \%$ of its weight. In the 9 th day the weight losses were about $0.8 \%$ per day.

The lab gas burner was placed under the center of the exposed surface. The temperatures were measured with three thermocouples MTC 10 type K. The first one measured the temperature of the $12 \mathrm{~mm}$ thick steel element. The second one was placed on the center of the exposed surface. The third one was

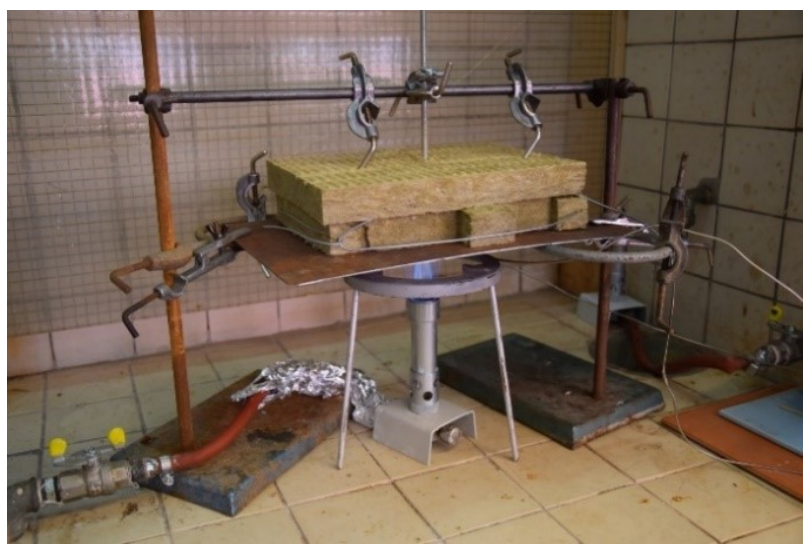

FiguRE 4. Experiment setup.

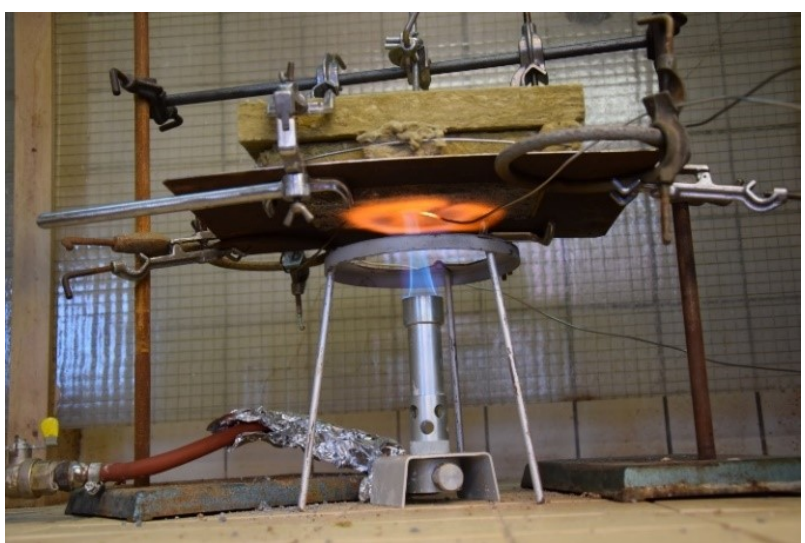

Figure 5. Experiment setup.

\begin{tabular}{|c|c|}
\hline \multicolumn{2}{|c|}{ H-cement mortar } \\
\hline bulk density & $335 \mathrm{~kg} \cdot \mathrm{m}^{-3}$ \\
\hline capacity & $1150 \mathrm{~J} \cdot \mathrm{kg}^{-1} \cdot \mathrm{K}^{-1}$ \\
\hline $\begin{array}{l}\text { conductivity } \\
\text { steel }\end{array}$ & unknown \\
\hline bulk density & $7850 \mathrm{~kg} \cdot \mathrm{m}^{-3}$ \\
\hline capacity & 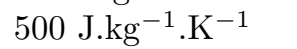 \\
\hline $\begin{array}{l}\text { conductivity } \\
\text { mineral wool }\end{array}$ & $46 \mathrm{~W} \cdot \mathrm{m}^{-1} \cdot \mathrm{K}^{-1}$ \\
\hline bulk density & $100 \mathrm{~kg} \cdot \mathrm{m}^{-3}$ \\
\hline capacity & $800 \mathrm{~J}^{\circ} \mathrm{kg}^{-1} . \mathrm{K}^{-1}$ \\
\hline conductivity & $0.041 \mathrm{~W} \cdot \mathrm{m}^{-1} \cdot \mathrm{K}^{-1}$ \\
\hline
\end{tabular}

TABLE 2. Simulation material parameters.

also on the exposed surface, but positioned close to the corner of the surface, see the photo in Figure 3 and a position scheme in Figure 7 .

All the three temperature curves are depicted in Figure 9. We hoped in reaching higher temperatures, but the thicknesses of the mortar and the steel element were too big and the experiment was stopped after 45 minutes, thus the temperature of the steel element reached only $167^{\circ} \mathrm{C}$. But the layer of $\mathrm{H}$-cement was in a state of high temperature, see the simulation results in Figure 11.

Immediately after the 45 minute fire load the mor- 


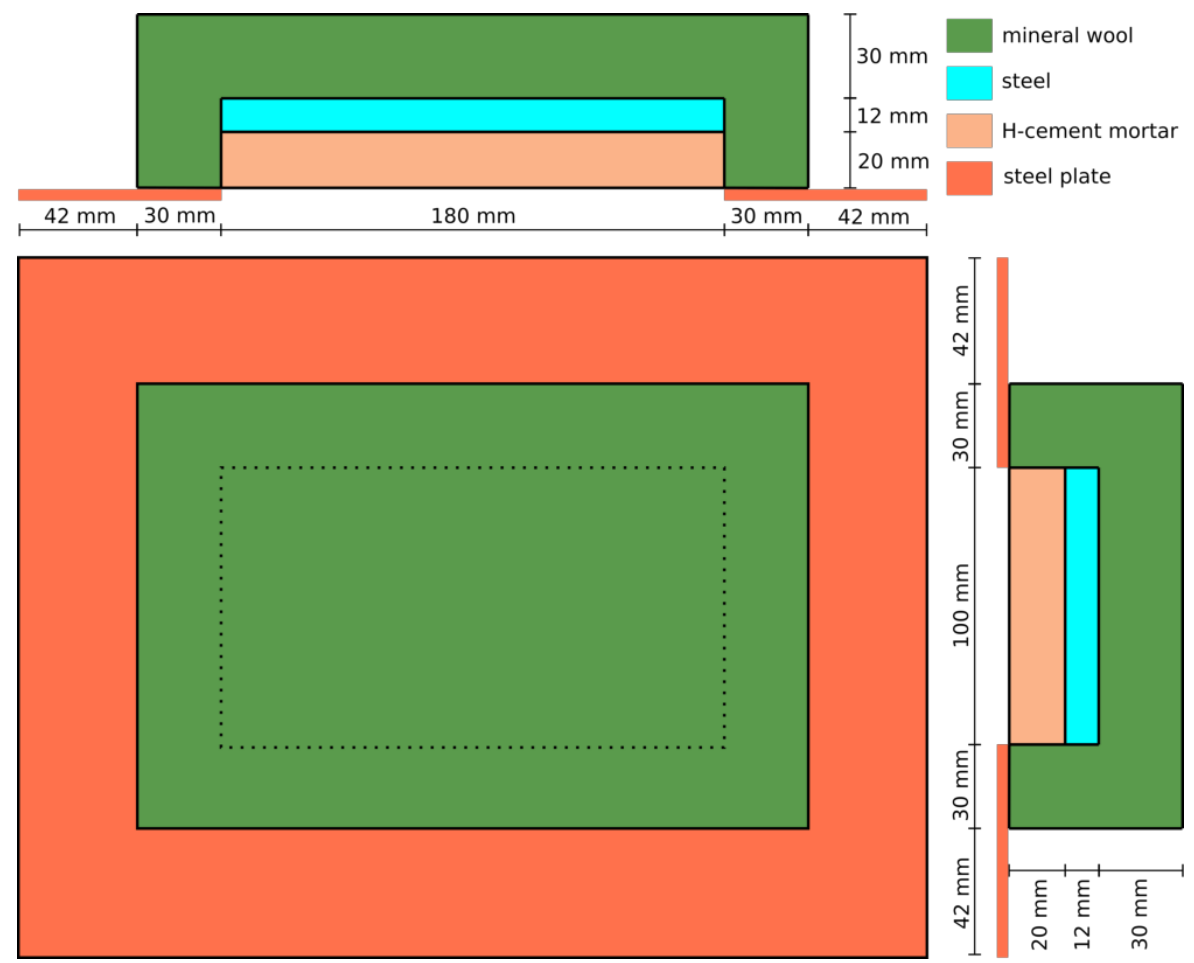

FiguRE 6. Geometry of the experiment.

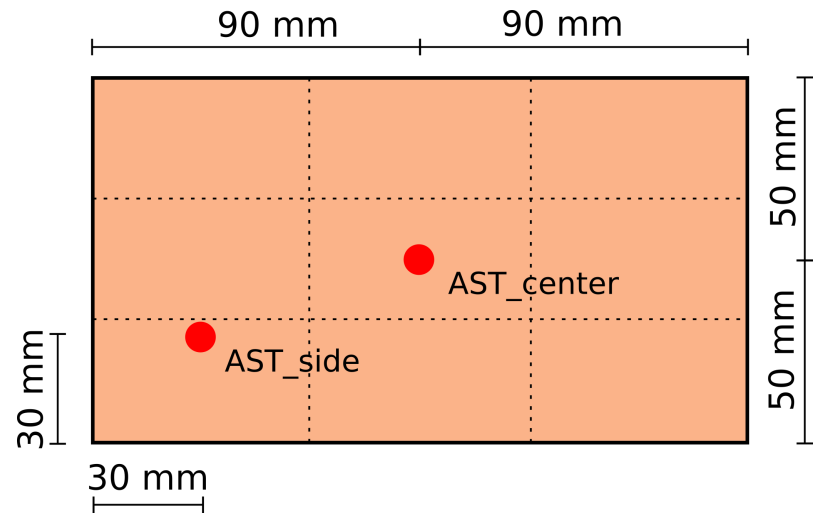

Figure 7. Position of the thermocouples on the exposed bottom surface. $3 \times 3 \mathrm{FEM}$ elements are indicated.

tar was put into water to test its mechanical resistance for this kind of immediate change of temperature, while the steel element remained just above water. The state of the mortar is shown in Figure 8 and shows no visible damage.

\subsection{Simulation}

The simulation was realized with OOFEM software [7]. The domain was composed of quadratic brick elements. The domain of steel member was composed of $3 \times 3 \times 1 \mathrm{FEM}$ elements. The domain of $\mathrm{H}$-cement was composed of $3 \times 3 \times 4$ elements. The thickness of mineral wool was divided into 3 elements. Material properties follow values from Table 2 .

The temperatures AST_center and AST_side are considered to be the "adiabatic surface temperatures"

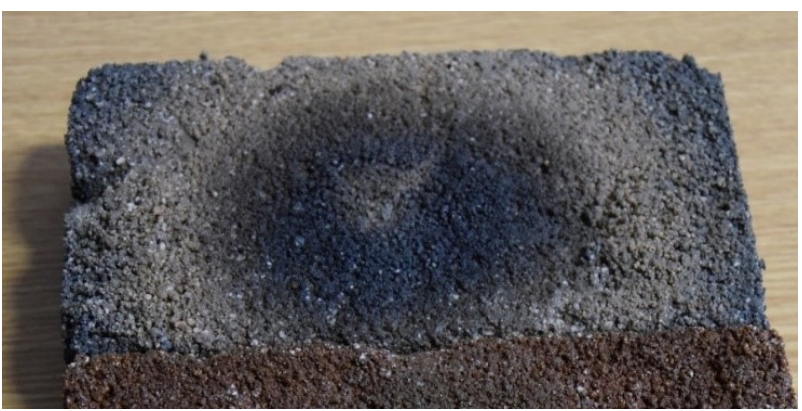

FiguRE 8. H-cement mortar after the experiment and after fast cooling in water.

and thus come into both convective and radiative boundary conditions on the exposed surface. The temperature AST_center is applied on the surface of the brick element in the center of the domain, while the rest of the exposed surfaces are loaded with the AST_side temperature. The element division is noticeable in Figure 7.

The initial temperature of the whole domain was $28.6{ }^{\circ} \mathrm{C}$. The outer temperature in boundary conditions of mineral wool surfaces was considered to be $30{ }^{\circ} \mathrm{C}$. The simulation was calculated with all timesteps being 1 second. The emissivity of exposed surfaces was 0.8 and the heat transfer coefficient was $20.0 \mathrm{~W} \cdot \mathrm{m}^{-2} \cdot \mathrm{K}^{-1}$.

The output of this simulation is a curve representing temperature of the steel element for given conductivity value of H-cement. Three curves for different values of conductivity are depicted in Figure 10 to show the impact of this parameter on the results. 


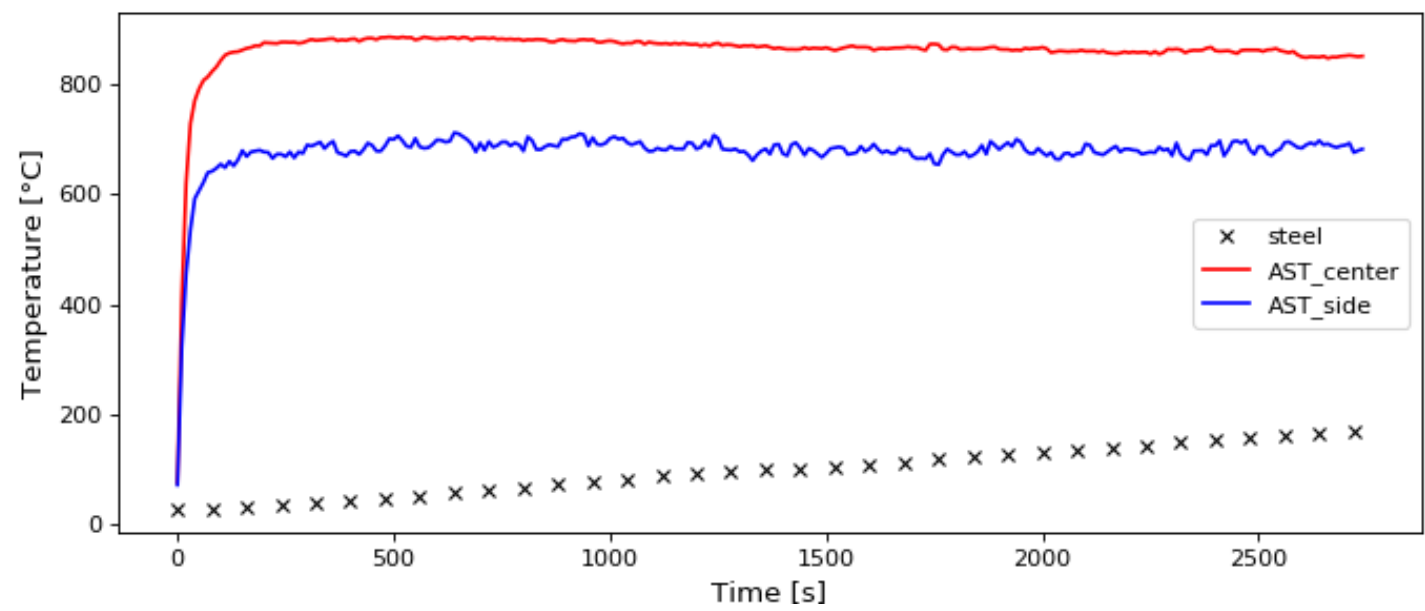

Figure 9. Adiabatic surface temperatures from the thermocouples and temperature of the steel element.

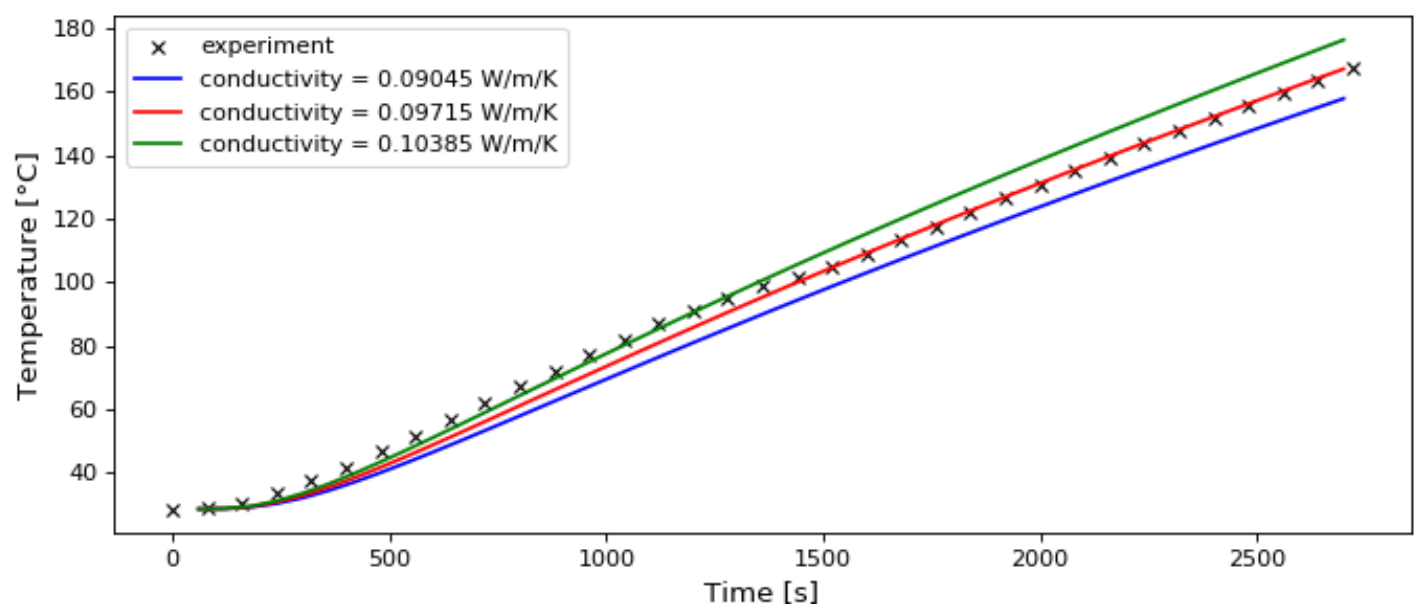

Figure 10. Temperature comparison for three values of H-cement conductivity.

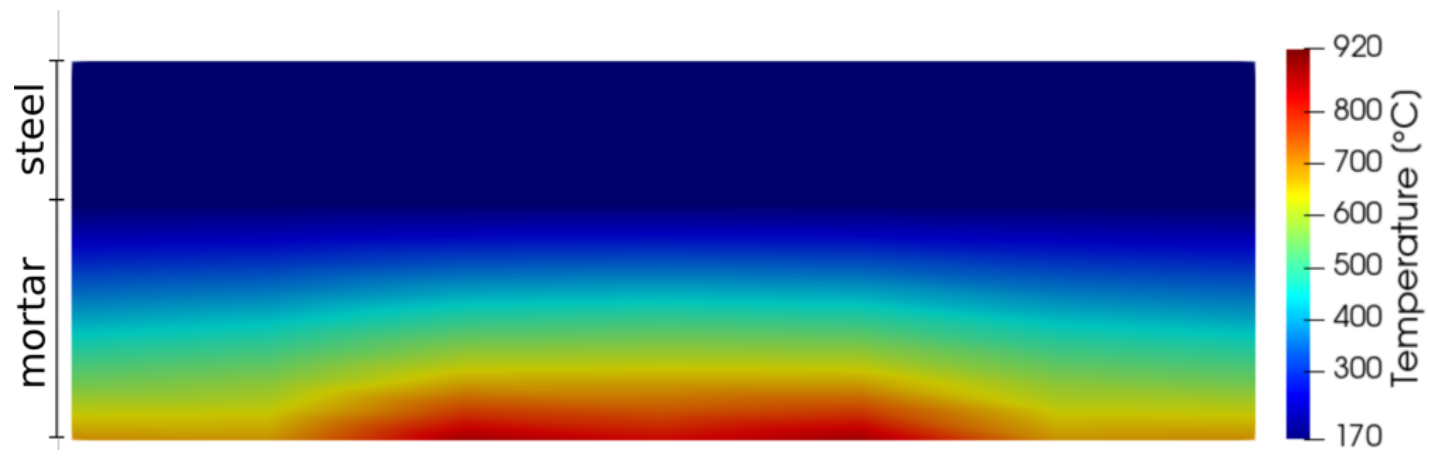

Figure 11. Temperature distribution at time $2700 \mathrm{~s}$.

According to the simulations, the thermal conductivity of this H-cement mortar is $0.09715 \mathrm{~W} . \mathrm{m}^{-1} . \mathrm{K}^{-1}$. These results slightly do not correspond with experimental data until $100{ }^{\circ} \mathrm{C}$ temperature is reached, which is caused by water content and its evaporation. After that moment the results match the experimental data very well and also seem to have the same tendency for higher temperatures, which were not reached in this experiment.

The temperature field in a section through the center of the domain at time $2700 \mathrm{~s}$ is presented in Fig-

\begin{tabular}{ll}
\hline H-cement mortar & \\
\hline bulk density & $335 \mathrm{~kg} \cdot \mathrm{m}^{-3}$ \\
capacity & $1150 \mathrm{~J} \cdot \mathrm{kg}^{-1} \cdot \mathrm{K}^{-1}$ \\
conductivity & $0.09715 \mathrm{~W} \cdot \mathrm{m}^{-1} \cdot \mathrm{K}^{-1}$ \\
\hline
\end{tabular}

TABLE 3. H-cement material parameters with conductivity yielding from the simulations.

ure 11. It shows that despite the low resulting temperature of the steel element, the temperature of the 
mortar has reached quite high values. However, it would need another experiment to show its behavior on its limit at much higher temperatures, but it should be completely different experiment setup with another fuel.

\section{Conclusions}

$\mathrm{H}$-cement is a material with promising characteristics and resistance to high temperatures during fire. This article determined its thermal properties based on a simple experiment with a lab gas burner and it also showed its behavior during fire load with temperatures comparable with the standard temperature curve ISO 834.

In principle, once we know the thermal material properties, simulations can replace the experiments in the process of design of fire protection. But more experiments with higher temperatures must be done to have data about the material behavior at full possible temperature range. The material will be further tested and analysed to find its strongest sides and its most suitable applications.

\section{ACKNOWLEDGEMENTS}

This research was funded by Czech Science Foundation, grant 19-22435S "Performance of structures with timber fire protection - multi-physics modelling" and also by Czech Technical University in Prague, grant number SGS20/038/OHK1/1T/11.

\section{REFERENCES}

[1] G. Li, P. Wang. Properties of steel at elevated temperatures. Advanced Analysis and Design for Fire Safety of Steel Structures 2013. DOI:https://doi.org/10.1007/978-3-642-34393-3_3.

[2] Z. Nie, Y. Li, Y. Wang. Mechanical properties of steels for cold-formed steel structures at elevated temperatures. Advances in Civil Engineering 2020.

[3] P. Martauz, I. Janotka, J. Strigáč, M. Bačuvčík. Fundamental properties of industrial hybrid cement: utilization in ready-mixed concretes and shrinkagereducing applications. Materiales de Construccion, 2016.

[4] J. Daxner. Use of hybrid cement in fireresistant plasters. $88 \mathrm{KHI} / 2016,2016$.

[5] I. Hager. Behaviour of cement concrete at high temperature. Bulletin of the Polish Academy of Sciences, Technical Sciences 61, 2013.

[6] J.-C. Mindeguia, P. Pimienta, H. Carré, C. L. Borderie. Experimental analysis of concrete spalling due to fire exposure. European Journal of Environmental and Civil Engineering 2013. DOI:10.1080/19648189.2013.786245.

[7] OOFEM https://oofem.org, 2020. 